\title{
A Book Review: Sustainable Human Resource Management by Senior Prof. Dr. Henarath H.D.N.P. Opatha
}

\author{
A. S. Dharmasiri \\ Postgraduate Institute of Management
}

\section{Overview}

There is a growing awareness and enthusiasm on people management in Sri Lankan organizations. This is evident by the increasing number of activities related to Human Resource Management (HRM) in many fronts taking place in the island. Yet, we have a long way to go in unleashing the true potential of our productive workforce, in the wake of a post-war economic expansion and development drive. One key element in such an endeavor is to have clarity of what really HRM is all about and its broad dimensions. Senior Prof. Henarath Opatha has fulfilled a felt void in presenting a prolific volume on "Sustainable HRM".

As he mentioned clearly, "the objective of this book is to provide a systematic and rational understanding of Sustainable HRM based on a model developed by me, both conceptual understanding and application-oriented understanding to the reader". As he further states, "it delivers a systematic approach to the analysis and handling of major issues in Sustainable HRM".

\section{Sustainability to the Forefront}

Sustainability has multiple fronts. The author observes that the terms sustainable development", "sustainability", "corporate sustainability" and "corporate social responsibility (CSR)' have been utilized interchangeably. As it is popularly known, the name sustainability is derived from the Latin sustainer meaning to "maintain", "support", or "endure". Since the 1980s sustainability has been used more in the sense of human sustainability on planet Earth and this has resulted in the most widely quoted definition of sustainability as a part of the concept

\section{Corresponding Author:}

Prof. Ajantha. S. Dharmasiri is the Director of Postgraduate Institute of Management. Email: director@pim.sjp.ac.lk 
sustainable development, that of the Brundtland Commission of the United Nations on March 20, 1987: "sustainable development is development that meets the needs of the present without compromising the ability of future generations to meet their own needs."

As the author observes, "this is the widely used definition and the Commission highlighted three fundamental components of sustainable development, i.e. the economic growth, the environmental protection, and social equity". "Hence sustainable future needs to be economically viable, environmentally sound, and socially equitable." He also cites the International Institute for Sustainable Development presented a business definition of sustainable development in its report, in 1992 as follows: "Adopting business strategies and activities that meet the needs of the enterprise and its stakeholders today while protecting, sustaining and enhancing the human and natural resources that will be needed in the future."

The author having perused through multiple ways of describing sustainability presents his definition: "Deliberate constant endeavor to utilize human and other resources, and natural environment to meet needs of current stakeholders of the organization while maintaining and if possible enhancing human and other resources, and natural environment to meet the needs of future stakeholders. "

\section{Sustainable HRM in Focus}

Senior Prof. Opatha cites many previous authors who attempted to describe Sustainable HRM and summaries what has been captured so far. "Sustainable HRM is the utilization of HRM tools to help embed a sustainability strategy in the organization and the creation of an HRM system that contributes to the sustainable performance of the firm. Sustainable HRM creates the skills, motivation, values and the trust to achieve a triple bottom line and at the same time ensures the long-term health and sustainability of both the organizations internal and external stakeholders with policies that reflect equity, development and well-being and help support environmentally friendly practices."

In essence, it is how HRM proactively responds to the creation of triple bottom line, profit, people and planet. As the author presents his own definition of Sustainable HRM, "it is that part of Human Resource Management which is concerned with planet-related matters, society-related matters and profit-related matters. Its aim is to maximize environmental, social, and economic performance 
of the organization. It refers to the policies, procedures, rules, practices and systems of managing employees which contribute to achieve sustainability."

It is interestingly to observe how Senior Prof. Opatha divides three subbranches of Sustainable HRM. They are termed as Green HRM (Planet related matters), Social HRM (Society related matters) and Economic HRM (Profitrelated matters). As he identifies, Green HRM includes green roles of employees, green HRM functions, green attitude and behavior, green job performance etc. Social HRM includes organizational ethics, work-family balance, quality of work life, health and safety and employee counselling, happiness etc. Economic HRM includes high performance organization, employee retention, absenteeism and presenteeism, customer satisfaction, competitive business strategy and HR strategy etc. Obviously, such an approach captures a vast array of affairs in the broad gamut of HRM.

\section{Key Features of the Book}

Sustainable HRM is a comprehensive volume that consists of twelve chapters. Each of the chapters contain chapter objectives and summary, useful frameworks, instruments developed by the author to measure various Sustainable HRM constructs, real-life and interesting examples, review questions, activities (cases, critical incidents, and skill builders) and a glossary of key terms.

Among the interesting topics, sustainability and HRM, green HRM, organizational ethics and HRM, work-family balance, quality of work-life, employee counselling and happiness, and HRM can be stated. I see the chapter on happiness, particularly insightful with wide ranging aspects such as psychological well-being. Pathway to happiness has been stated as a pleasant life, good life and a meaningful life. The role of HRM in creating employee happiness has been adequately dealt with by the author.

As the book intended to be more of a text book, the appeal is more for the students and researchers. As an improvement for a future revision, adding more practical relevance by way of contemporary local and global examples can be proposed. It is by no means undermining the pioneering contribution in bringing a strategically significant publication to the forefront. As the author himself mentions in his foreword: "May this book contribute to increase learning and teaching of Sustainable HRM among students, professionals and university and college teachers, and finally to enhance environmental, social, and economic 
sustainability! This is my heart- felt wish. Any suggestions for the improvement of the book are welcome".

\section{Further Reflections}

Sustainable HRM is required in a decisive way. Aptly intertwined with the consciousness of profit, people and planet, it should be viewed holistically in the broad context of socio-economic and religion-cultural fabric of Sri Lanka. It should cater for organizational progress, societal well-being and ecological conservation.

The terms I coined some time ago to depict triple trends of future HRM, as be lean, seen and green aptly fits with Senior Prof. Opatha's concept of Sustainable HRM. Be lean is for economic HRM being cost-effective catering for higher profitability. Be seen is for Societal HRM having the visibility factor in connecting to people in responding to their needs. Be green is obviously connected to green HRM.

The conventional mindset of "labor handling" should pave way for creative mindset of "talent engagement" in multiple useful fronts. Are Sri Lankan HR professionals ready for such a challenging change with a broader awareness? Are private sector managers and public sector administrators willing to embrace such a mindset expansion? Are Sri Lankan leaders inspiring such change with timely decision making? These are the pertinent questions that need prompt attention, if sustainable HRM to move beyond a theoretical treatise.

\section{Way Forward}

As a life-long learner of HRM, let me appreciate the committed contribution of Senior Prof. Opatha towards humanity. May he engage in more such scholarly projects, preferably with more practical relevance.

It reminds me what Josiah Charles Stamp stated. "It is easy to dodge our responsibilities, but we cannot dodge the consequences of dodging our responsibilities". Senior Professor Dr. Henarath Hettiarachchige Desapriya Nandana Pushpakumara Opatha has done his part with ecological, ethical and economical consciousness. Now it is our turn to read, reflect and refresh ourselves in gearing towards meaningful sustained results. 